\title{
sciendo
}

\section{Graves' disease with spontaneous resolution following ocrelizumab in primary progressive multiple sclerosis}

\author{
Diana Borges Duarte ${ }^{1}$, Ana Martins da Silva ${ }^{2}$, Claudia Freitas ${ }^{1}$, Helena Cardoso ${ }^{1}$ \\ ${ }^{1}$ Department of Endocrinology, Diabetes and Metabolism, Centro Hospitalar e Universitario do Porto, Oporto, Portugal; \\ ${ }^{2}$ Department of Neurology, Centro Hospitalar e Universitario do Porto, Oporto, Portugal \\ E-mail: diana.sbduarte@gmail.com
}

Objectives. Immune reconstitution therapies (IRT), which include antibody-based cell-depleting therapies targeting CD52+ (alemtuzumab) or CD20+ (rituximab, ocrelizumab) leukocytes, are approved for the treatment of multiple sclerosis. Thyroid autoimmunity is a common adverse effect of alemtuzumab treatment, Graves' disease (GD) being the most prevalent manifestation. To date, thyroid autoimmunity events have not been reported with CD20-targeting monoclonal antibodies.

Case Report. A 59-year-old woman with primary progressive multiple sclerosis with no prior personal history of thyroid disease or autoimmunity, was diagnosed with GD 6 months following the first ocrelizumab infusion. She was asymptomatic and had no signs of ophthalmopathy. Due to the temporal association of GD diagnosis with ocrelizumab infusion, absence of symptoms and our experience with alemtuzumab-induced GD, we decided for an active surveillance strategy and antithyroid drugs were not started. She underwent spontaneous resolution of hyperthyroidism with thyroid-stimulating hormone (TSH) receptor antibodies (TRAb) negativity and a mild and transitory period of subclinical hypothyroidism, while she continued the biannually ocrelizumab administration schedule. To present date, she has maintained close clinical and biochemical surveillance with normal TSH, free thyroxine (fT4) and free triiodothyronine (fT3) levels and undetectable TRAb.

Conclusions. This is the first case of GD reported after ocrelizumab administration. The timing, onset and course of this case is similar to alemtuzumab-induced GD, usually interpreted as an "immune reconstitution syndrome"; however, ocrelizumab cell count depletion is inferior in severity, cell population affected and duration of depletion. This case highlights the importance of pre-screening and follow-up with thyroid function tests in patients treated with ocrelizumab. As a novel therapeutic antibody, further investigation is required to unravel the causes of thyroid autoimmunity.

Key words: ocrelizumab, Graves' disease, immune reconstitution therapy, multiple sclerosis

Multiple sclerosis (MS) is a chronic inflammatory and demyelinating neurodegenerative disease of the central nervous system. Both experimental and clinical evidence suggests that this is an autoimmune disease driven by dysregulation of the adaptive immune response (Lunemann et al. 2020).
The development of immune reconstitution therapies (IRTs), which include antibody-based celldepleting therapies targeting CD52+ (alemtuzumab) or CD20+ (rituximab, ocrelizumab) leukocytes, aim to, through an intense short-term immunosuppression or immune cell depletion, rebuild a new

Corresponding author: Diana Borges Duarte, Full name: Diana Sofia Borges Duarte, Department of Endocrinology, Diabetes and Metabolism, Centro Hospitalar e Universitario do Porto, Largo do Prof. Abel Salazar, 4099-001 Porto, Portugal; 
immune system with a re-established immune tolerance (Lunemann et al. 2020). Post-alemtuzumab treatment, $30-48 \%$ of patients develop secondary autoimmunity, thyroid autoimmunity (TA) being the commonest and interpreted as an "immune reconstitution syndrome” (Muller et al. 2018). Graves' disease (GD) is the most prevalent form of alemtuzumabinduced TA. The distinctive course and features of alemtuzumab-induced GD have been highlighted in recently published clinical management guidelines (Muller et al. 2019).

Ocrelizumab, a second-generation humanized therapeutic antibody, targets the CD20 antigen expressed by a broad range of $\mathrm{B}$ cells and approximately $5 \%$ of T cells. It is approved for the treatment of relapsing and primary progressive forms of MS (Lunemann et al. 2020). To date, TA has not been reported in patients treated with CD20 targeting monoclonal antibodies (Muller et al. 2019; Lunemann et al. 2020).

In the present study, a case of GD diagnosed following ocrelizumab administration that underwent spontaneous resolution is reported. The patient provided written informed consent for the anonymous publication of her medical data.

\section{Case report}

A 59-year-old female was diagnosed with primary progressive multiple sclerosis (PPMS) in 2007; she was on dalfampridine for symptom management and had no previous immunomodulatory treatment.
Due to active disease on magnetic resonance imaging and progressive complaints of gait impairment and bladder dysfunction, she was started on ocrelizumab in July 2018 (split into two $300 \mathrm{mg}$ IV infusions two weeks apart). She was a non-smoker, had no prior personal or family history of thyroid disease, and her thyroid function tests were normal (Table 1).

In January 2019, at the time of her second ocrelizumab administration (delivered as a single $600 \mathrm{mg}$ IV infusion), her thyroid function tests revealed an overt hyperthyroidism (thyroid-stimulating hormone, TSH: $0.02 \mu \mathrm{UI} / \mathrm{mL}$, reference range 0.27 $4.2 \mu \mathrm{UI} / \mathrm{mL}$; free triiodothyronine, fT3: $8.26 \mathrm{pg} /$ $\mathrm{mL}$, reference range $2.0-4.4 \mathrm{pg} / \mathrm{mL}$; free thyroxine, fT4: $4.64 \mathrm{ng} / \mathrm{dL}$, reference range $0.93-1.7 \mathrm{ng} / \mathrm{dL}$ ), for which she was referred to our Endocrinology outpatient clinic. At our first observation she presented normal blood pressure and heart rate, no visible goiter, or palpable nodules, with no symptoms of thyrotoxicosis nor signs of Graves' ophthalmopathy (GO), confirmed after ophthalmologist examination. Our subsequent investigation showed strong autoantibody positivity for TSH receptor antibodies (TRAb) and thyroid peroxidase (TPOAb). However, while maintaining low TSH, her fT4 and fT3 levels were already normal two months after her first abnormal thyroid function test.

Due to the absence of thyroid disfunction's symptoms, the temporal association of GD onset with ocrelizumab infusion, and our experience with alemtuzumab-induced GD, with a frequently unpredictable course and occasional rapid evolution to hypo-

Table 1

Lymphocyte count, thyroid function test and autoantibodies measurement before treatment with ocrelizumab and during follow-up

\begin{tabular}{lcccccccccc}
\hline & $\begin{array}{c}\text { February } \\
\mathbf{2 0 1 8}\end{array}$ & $\begin{array}{c}\text { July } \\
\mathbf{2 0 1 8}\end{array}$ & $\begin{array}{c}\text { January } \\
\mathbf{2 0 1 9}\end{array}$ & $\begin{array}{c}\text { March } \\
\mathbf{2 0 1 9}\end{array}$ & $\begin{array}{c}\text { June } \\
\mathbf{2 0 1 9}\end{array}$ & $\begin{array}{c}\text { August } \\
\mathbf{2 0 1 9}\end{array}$ & $\begin{array}{c}\text { October } \\
\mathbf{2 0 1 9}\end{array}$ & $\begin{array}{c}\text { January } \\
\mathbf{2 0 2 0}\end{array}$ & $\begin{array}{c}\text { July } \\
\mathbf{2 0 2 0}\end{array}$ & $\begin{array}{c}\text { November } \\
\mathbf{2 0 2 0}\end{array}$ \\
\hline $\begin{array}{l}\text { Lymphocyte count } \\
\left(1.5-4.0 \times 10^{3} \mu \mathrm{L}\right)\end{array}$ & 2.11 & 2.52 & 2.16 & $\mathrm{NM}$ & 1.49 & 1.69 & 2.08 & 1.76 & 2.52 & $\mathrm{NM}$ \\
$\begin{array}{l}\text { TSH } \\
(0.27-4.2 \mu \mathrm{UI} / \mathrm{mL})\end{array}$ & 1.88 & $\mathrm{NM}$ & 0.02 & 0.04 & 2.88 & 7.07 & 6.51 & 2.89 & 2.40 & 2.94 \\
$\begin{array}{l}\text { fT4 } \\
(0.93-1.7 \mathrm{ng} / \mathrm{dL})\end{array}$ & 1.12 & $\mathrm{NM}$ & 4.64 & 1.16 & 0.90 & 1.05 & 0.87 & 0.90 & 0.94 & 0.97 \\
$\begin{array}{l}\mathrm{fT} 3 \\
(2.0-4.4 \mathrm{pg} / \mathrm{mL})\end{array}$ & 2.86 & $\mathrm{NM}$ & 8.26 & 3.51 & 3.15 & 3.63 & 3.41 & 3.20 & 3.39 & 2.15 \\
$\begin{array}{l}\text { TRAb } \\
(<1.22 \mathrm{U} / \mathrm{L})\end{array}$ & $<0.3$ & $\mathrm{NM}$ & $\mathrm{NM}$ & 36.5 & 4.11 & $<0.3$ & $<0.3$ & $<0.3$ & $<0.3$ & $<0.3$ \\
$\begin{array}{l}\text { TPOAb } \\
(<34 \mathrm{UI} / \mathrm{mL})\end{array}$ & 5.5 & $\mathrm{NM}$ & $\mathrm{NM}$ & $>600$ & 36.2 & $\mathrm{NM}$ & $\mathrm{NM}$ & $\mathrm{NM}$ & $\mathrm{NM}$ & $\mathrm{NM}$ \\
$\begin{array}{l}\text { TgAb } \\
(<115 \mathrm{UI} / \mathrm{mL})\end{array}$ & $<10$ & $\mathrm{NM}$ & $\mathrm{NM}$ & 65.8 & 14.4 & $\mathrm{NM}$ & $\mathrm{NM}$ & $\mathrm{NM}$ & $\mathrm{NM}$ & $\mathrm{NM}$ \\
\hline
\end{tabular}

Abbreviations: fT3 - free triiodothyronine; fT4 - free thyroxine, NM - not measured; Tg- $\mathrm{Ab}$ - antibodies against thyroglobulin; $\mathrm{TPOAb}$ - antibodies against thyroid peroxidase; TSH - thyroid-stimulating hormone; TRAb - antibodies against TSH receptor. 
thyroidism, we decided for an active surveillance strategy and the patient was not started on antithyroid drugs (ATD). In June 2019 (6 months after GD diagnosis) her thyroid ultrasound revealed a normalsized gland with homogeneous parenchyma and no signs of increased vascularization with a single hypoechogenic nodule on the posterior region of the right lobe with $16 \mathrm{~mm}$ at the largest diameter. Thyroid scintigraphy with ${ }^{99 \mathrm{~m}} \mathrm{Tc}$-sestamibi showed a homogeneous distribution of the radiotracer. Fine needle aspiration cytology was benign (Bethesda diagnostic category II). She was then clinical and biochemically euthyroid with decreasing titles of both TRAb and TPOAb.

Given the favorable evolution of GD, the scheduled third and fourth ocrelizumab administration were given on July 2019 and February 2020. She remained asymptomatic while experiencing a mild and transitory period of subclinical hypothyroidism with negative TRAB in August and October of 2019. To present date, she has maintained close clinical and biochemical surveillance with normal TSH, fT4 and fT3 levels and undetectable TRAb.

\section{Discussion}

In 2017, ocrelizumab became the first approved drug for PPMS after the ORATORIO trial favored ocrelizumab over placebo with respect to the risk of confirmed disability progression at 12 weeks, the primary end point. The most frequently reported adverse event was infusion-related reaction, followed by infections, mainly in the upper respiratory tract (Montalban et al. 2017). To date no secondary autoimmune disease had been described.

We report a case of Graves' disease following ocrelizumab therapy. Our patient presented with overt hyperthyroidism with strong TRAb positivity six months following the first ocrelizumab infusion. She was asymptomatic, had no GO and exhibited a spontaneous reversion to an euthyroid status with TRAb negativity.

This case has unique features to address. This is an IRT naive patient with no prior history of thyroid disease or dysfunction nor evidence of TA. The most obvious question is whether GD was induced or eventually treated by ocrelizumab. Graves' disease incidence is increased in MS patients (Antonelli et al. 2020) and so the hypothesis of a sporadic GD cannot be excluded. However, we find it unlikely considering the timing of diagnosis and the resolution of an overt hyperthyroidism without treatment with ATD. Could ocrelizumab exert a role in GD resolu- tion? An older CD20-targeting therapy, rituximab, has been proposed for treatment of active GO (Salvi et al. 2007). A review of the literature was conducted to analyze the available evidence of rituximab effect on thyroid function and GD treatment. In a trial designed to compare rituximab and methylprednisolone in patients with moderate to severe GO (previously rendered euthyroid by ATD) serum TRAb levels in rituximab-arm did not differ from those observed in the methylprednisolone group at the end of follow-up period (Salvi et al. 2015); thyroid function levels were also not affected by rituximab treatment, as shown previously by the same authors (Salvi et al. 2007). In a nonrandomized pilot study, 20 patients with GD were rendered euthyroid with methimazole and then assigned to rituximab or observation alone; while rituximab decreased the risk of relapse, the reduction in TRAb levels was similar between the two groups (el Fassi et al. 2007). However, thyroidstimulating immunoglobulin activity reduced significantly only in the rituximab group (el Fassi et al. 2009). Another single-arm study with 13 patients (9 were responders) found indications for a beneficial effect of rituximab in patients with relapsing GD with mild hyperthyroidism (Heemstra et al. 2008). Finally, we also found a case report describing a possible GD-remission after rituximab administration for pancreatic $\beta$-cell protection in a patient with type 3 autoimmune polyglandular syndrome; the patient was previously treated with ATD and potassium iodide; GD remission was achieved 4 months after the rituximab administration (Kurozumi et al. 2015). Overall, evidence favoring a role of rituximab in the treatment of GD is still scarce and mostly based on single-arm studies with patients previously treated with ATD to achieve an euthyroid status. The persistence of plasma cells, which do not express CD20, may explain why autoantibodies levels are not affected.

The circumstances, onset and course (delayed onset with transient dysfunction with spontaneous resolution) are similar to IRT-induced TA (Muller et al. 2019); the timing of diagnosis favors an ocrelizumab induced etiology more than a sporadic form. However, despite the similarities with IRT-induced TA, ocrelizumab targets different immunological cell populations when compared to alemtuzumab, the hallmark drug associated with immune reconstitution syndrome.

The onset of GD implicates a breakdown of immune tolerance towards the thyroid, through an autoimmune multifactorial process, in which there is a failure to detect TSH-receptor-reactive T and B cells 
(Weetman 2009; Antonelli et al. 2020). Although GD is traditionally viewed as a result of humoral immunity, by inducing a rise of TRAb, T (CD4+ and CD8+) cells are involved in autoimmunity induced by IRT (Muller et al. 2019).

Reconstitution Graves' disease has been observed after bone marrow transplantation, following restoration of $\mathrm{CD} 4+\mathrm{T}$ cells in HIV-infected patients treated with highly active antiretroviral therapy and during the recovery phase of CD52+ cells depleted by alemtuzumab. Evidence shows that, during reconstitution autoimmunity, the cytokine milieu is biased towards a Th2 profile which would explain why autoantibody-mediated diseases are more common than destructive, Th1-mediated disorders such as Hashimoto's thyroiditis (Weetman 2009). Alemtuzumab causes a depletion of both $\mathrm{B}$ and $\mathrm{T}$ cells (including $\mathrm{CD} 4+$ and $\mathrm{CD} 8+$ ); however, the recovery of B cell counts occurs earlier (at 3-6months) while $\mathrm{T}$ cells count, particularly CD4+, remain below the lower limit of normal at 12 months. The hyperpopulation of $B$ cells, in the absence of T-cell regulation and the hyperpopulation of naive $\mathrm{B}$ cells with longlasting depletion of memory $\mathrm{B}$ cells could be responsible for the secondary B cell autoimmunity that can occur with alemtuzumab therapy. This autoimmunity requires T-cell involvement and so is unlikely to occur until $\mathrm{CD} 4+\mathrm{T}$ cell numbers regenerate to sufficient levels, resulting in a delay between B cell hyperreactivity and development of autoimmunity. Additionally, the recovery of $\mathrm{T}$ cells is predominantly a result of peripheral expansion (rather than thymic reconstitution), which favors immune cell populations that respond to self (Sellner and Rommer 2020).

With ocrelizumab there is a depletion of $\mathrm{B}$ cells and CD20+ T cell counts while CD4+ and CD8+ T cells count remain unchanged (Sellner and Rommer 2020). Hence, the hypothesis of an immune reconstitution Graves' disease may still be plausible but with a different pathophysiology. Evidence demonstrate that B-cell repopulation is made preferentially with immature or transitional B cells and that myeloid cell post-anti-CD20+ treatment have an enhanced activation status and pro-inflammatory differentiation (Hausler et al. 2018; Sellner and Rommer 2020). If any of these findings have a potential role on TA after ocrelizumab administration is still a matter of discussion.

As a limitation of our report, we identify the absence of measurement of stimulating or blocking subtypes of TRAb (the latter not available at our laboratory) as it could distinguish qualitative and not only quantitative changes.

Overall, this case highlights the importance of pre-treatment screening and follow-up with thyroid function tests in patients with MS treated with IRT in order to identify patients at risk and to promptly diagnose TA. This case might be the seminal finding of an ocrelizumab- induced TA manifested with Graves' disease. Once diagnosed, active surveillance seems a reasonable strategy, in the case of an asymptomatic patient, as spontaneous resolution of thyroid dysfunction is not uncommon. As a novel therapeutic antibody, further investigation is required to unravel underneath causes of TA with ocrelizumab.

\section{References}

Antonelli A, Fallahi P, Elia G, Ragusa F, Paparo SR, Ruffilli I, Patrizio A, Gonnella D, Giusti C, Virili C, Centanni M, Shoenfeld Y, Ferrari SM. Graves' disease: Clinical manifestations, immune pathogenesis (cytokines and chemokines) and therapy. Best Pract Res Clin Endocrinol Metab 34, 101388, 2020.

el Fassi D, Nielsen CH, Bonnema SJ, Hasselbalch HC, Hegedus L. B lymphocyte depletion with the monoclonal antibody rituximab in Graves' disease: a controlled pilot study. J Clin Endocrinol Metab 92, 1769-1772, 2007.

el Fassi D, Banga JP, Gilbert JA, Padoa C, Hegedus L, Nielsen CH. Treatment of Graves' disease with rituximab specifically reduces the production of thyroid stimulating autoantibodies. Clin Immunol 130, 252-258, 2009.

Hausler D, Hausser-Kinzel S, Feldmann L, Torke S, Lepennetier G, Bernard CCA, Zamvil SS, Bruck W, Lehmann-Horn K, Weber MS. Functional characterization of reappearing B cells after anti-CD20 treatment of CNS autoimmune disease. Proc Natl Acad Sci U S A 115, 9773-9778, 2018.

Heemstra KA, Toes RE, Sepers J, Pereira AM, Corssmit EP, Huizinga TWJ, Romijn JA, Smit JW. Rituximab in relapsing Graves' disease, a phase II study. Eur J Endocrinol 159, 609-615, 2008.

Kurozumi A, Okada Y, Arao T, Narisawa M, Torimoto K, Yamamoto S, Tanaka Y. Induction of thyroid remission using rituximab in a patient with type 3 autoimmune polyglandular syndrome including Graves' disease and type 1 diabetes mellitus: a case report. Endocr J 62, 69-75, 2015. 
Lunemann JD, Ruck T, Muraro PA, Bar-Or A, Wiendl H. Immune reconstitution therapies: concepts for durable remission in multiple sclerosis. Nat Rev Neurol 16, 56-62, 2020.

Montalban X, Hauser SL, Kappos L, Arnold DL, Bar-Or A, Comi G, de Seze J, Giovannoni G, Hartung HP, Hemmer B, Lublin F, Rammohan KW, Selmaj K, Traboulsee A, Sauter A, Masterman D, Fontoura P, Belachew S, Garren H, Mairon N, Chin P, Wolinsky JS; ORATORIO Clinical Investigators. Ocrelizumab versus placebo in primary progressive multiple sclerosis. N Engl J Med 376, 209-220, 2017.

Muller I, Willis M, Healy S, Nasser T, Loveless S, Butterworth S, Zhang L, Draman MS, Taylor PN, Robertson N, Dayan CM, Ludgate ME. Longitudinal characterization of autoantibodies to the thyrotropin receptor (TRAb) during alemtuzumab therapy: Evidence that TRAb may precede thyroid dysfunction by many years. Thyroid 28, 1682-1693, 2018.

Muller I, Moran C, Lecumberri B, Decallonne B, Robertson N, Jones J, Dayan CM. 2019 European Thyroid Association Guidelines on the management of thyroid dysfunction following immune reconstitution therapy. Eur Thyroid J 8, 173-185, 2019.

Salvi M, Vannucchi G, Campi I, Curro N, Dazzi D, Simonetta S, Bonara P, Rossi S, Sina C, Guastella C, Ratiglia R, Beck-Peccoz P. Treatment of Graves' disease and associated ophthalmopathy with the anti-CD20 monoclonal antibody rituximab: an open study. Eur J Endocrinol 156, 33-40, 2007.

Salvi M, Vannucchi G, Curro N, Campi I, Covelli D, Dazzi D, Simonetta S, Guastella C, Pignataro L, Avignone $S$, Beck-Peccoz P. Efficacy of B-cell targeted therapy with rituximab in patients with active moderate to severe Graves' orbitopathy: a randomized controlled study. J Clin Endocrinol Metab 100, 422-431, 2015.

Sellner J, Rommer PS. Immunological consequences of "immune reconstitution therapy" in multiple sclerosis: A systematic review. Autoimmun Rev 19, 102492, 2020.

Weetman A. Immune reconstitution syndrome and the thyroid. Best Pract Res Clin Endocrinol Metab 23, 693-702, 2009. 